\title{
Multi-Response Optimization of Post-Fire Residual Properties of High Performance Concrete
}

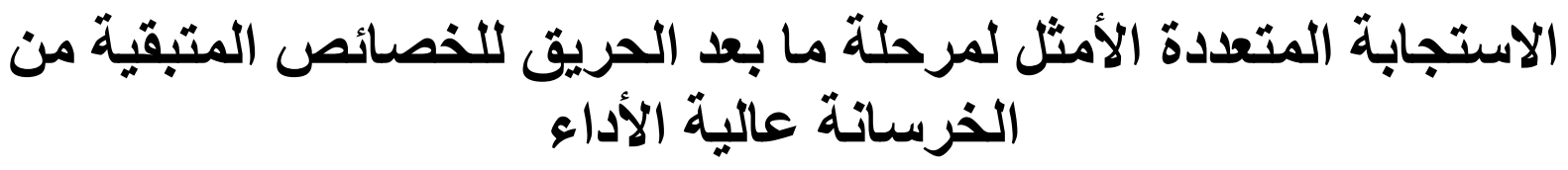

\author{
S. H. Zoalfakar ${ }^{a^{*}}$, Mona. A. Elsissy ${ }^{\mathrm{b}}$ and Y.B Shaheen, \\ $\mathrm{a}^{*}$ Assist. Prof, Department of Mechanical Engineering, the Higher Technological \\ Institute $10^{\text {th }}$ of Ramadan City, EGYPT. \\ ${ }^{\mathrm{b}}$ Assist. Prof, Nile Institute for Engineering, Mansoura, Egypt. \\ Prof. of strength and testing of materials, Department of Civil Engineering, \\ Faculty of Engineering, Menoufiya University, Shebin El-Kom, EGYPT, \\ E-mail: ( ${ }^{*}$ Said_hussien2005@yahoo.com)
}

Institute Tel.: +2015363498 Fax: +2015364183, Mobile: +201006791408

*Corresponding author. (Said H. Zoalfakar), Mechanical Engineering Department, Higher Technological Institute, 10th of Ramadan City, Egypt, Email address: Said_hussien2005@yahoo.com Tel/Fax:+2015364183.

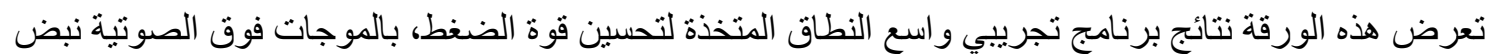

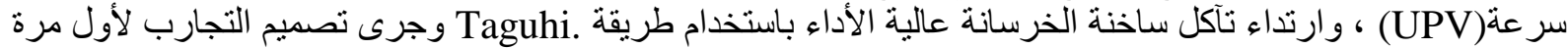

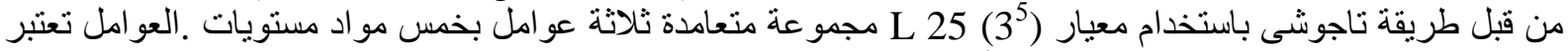

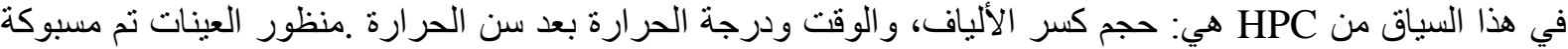

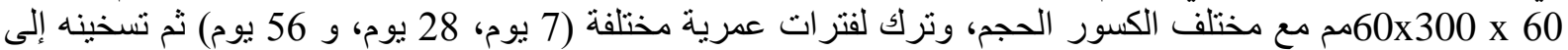

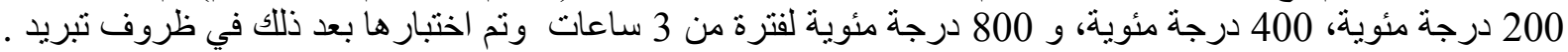
وبناء على النتائج التجريبية، والمواد تم تحليل استجابات المعلمة ومستوى إذا تم تحديد أهمية معلمات الإدخال على في فيم

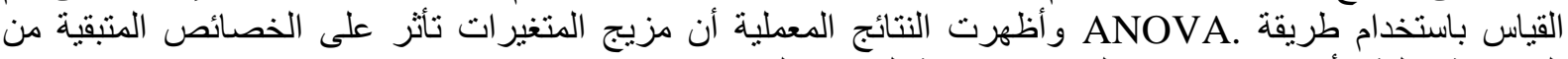
الخرسانة عالية الأداء (HPC) مع التغير في درجة الحر ارة التهرة التعرض.

\section{Abstract}

This paper presents the results of an extensive experimental program undertaken to optimize compressive strength, ultrasonic pulse velocity (UPV), and abrasion wear of heated high performance concrete using Taguhi method and the utility concept. The design of experiments (DOEs) was first carried out by Taguchi method using a standard L $25\left(3^{5}\right)$ orthogonal array of three factors with five materials parameters levels. The factors considered in this context of HPC were: fiber volume fracture, age time and post-heat temp. The prism specimens 60x60x300 mm with various volume fractions were casted, left for different age times (7 day, 28 day, and 56 day) then heated up to $200{ }^{\circ} \mathrm{C}, 400{ }^{\circ} \mathrm{C}$, and $800{ }^{\circ} \mathrm{C}$ for a time of $3 \mathrm{hrs}$ then they were subsequently tested in the cooled conditions. Based on the experimental results, the materials parameter responses were analyzed.

\section{Keywords}

Lightweight; Mechanical properties; Analysis of variance (ANOVA); Optimization; Taguchi method

\section{Introduction}

The use of high performance concrete (HPC) in building construction increased significantly during the last quarter of the $20^{\text {th }}$ century. High performance concrete exhibits significantly higher compressive strengths than normalstrength concrete (NSC), which allows for extensions of structural design by allowing structural members made from HPC to carry higher loads [1]. As a result of its increased application in many areas of 
construction, studies are being conducted to define better the properties of HPC and to develop a better understanding of its use. These studies are directed at producing a technical database for full exploitation of HPC construction materials. As a part of these studies work is underway to develop data on the thermal performance of HPC materials. Some of this work addresses the thermal performance of HPC as it relates to reported cases of explosive spalling. This high potential for spalling has been reported in cases where HPC is subjected to rapid heating [1]. An example of HPC being more susceptible to spalling was in the Eurotunnel during a railcar fire on November 18, 1996. The fire brigades from France and the United Kingdom reported that the tunnel's concrete liner caused dangers from sapling while rescue and firefighting activities were underway [2]. Reports from the fire brigades and investigations following the fire indicated that the thermal performance of HPC needed further study [2][3]. Concerns identified by these early HPC reports highlighted the difference in the behavior of HPC compared to NSC when exposed to elevated temperatures. This difference in thermal behavior can have an impact on structural design considerations related to fire performance and on the safety of fire service personnel.

Lightweight aggregates are broadly classified into two types - natural (pumice, diatomite, volcanic cinders, etc.) and artificial (perlite, expanded shale, clay, slate, sintered PFA, etc.). Lightweight concrete can easily be produced by utilizing natural lightweight aggregate, i.e., pumice or perlite aggregate [4].

Mydin and Soleimanzadeh [5] studied the effect of adding polypropylene fiber (PF) with volume fractions of 0.1 , $0.2,0.3,0.4,0.45$ and $0.5 \%$ on the flexural strength and pore structure of each considered density at ambient and elevated temperatures up to $600{ }^{\circ} \mathrm{C}$. Increasing temperature had a detrimental influence on lightweight foamed concrete (LFC) property especially in a temperature range of 200 to $600{ }^{\circ} \mathrm{C}$ degrees in which flexural resistance was reduced by about 15 to $60 \%$ due to the micro diffusion of bound water molecules, detachment of the C-S-H gel and $\mathrm{CH}$, weakness in chemical bond structure of cement paste and suppresses of the cohesive forces in the micropores. At each predetermined temperature, LFC with higher density achieved higher bending resistance as it had smaller and more uniform voids compared to LFC with lower density and higher loads were required to break it down. Adding PF by $0.1-0.4 \%$ of mix volume enabled LFC to resist high temperatures better than control plain concrete and the improvement percentage was directly correlated with $\mathrm{PF}$ content and LFC density. However, adding $\mathrm{PF}$ with volume fraction more than $0.4 \%$ reduced the flexural strength considerably. At ambient temperature, the larger content of PF led to an increased amount of pores in concrete structure and at elevated temperature a larger number of cracks was induced due to evaporation of more fibers and replacement of them by air voids led to significant reduction in flexural strength of LFC [5].

Design of experiments is a power analysis tool for modeling and analyzing the influence of process variables over some specific variable [6]. The most important stage in the design of experiment lies in the selection of the control factors. As many as possible should be included, so that it would be possible to identify nonsignificant variables at the earliest opportunity [7]. Rahim et al. [8] examined the statistically significant parameters of mix proportions of fly ash based high performance concrete in order to maximize the residual compressive strength of heated concrete. While mono performance characteristics optimization process was established by Taguchi technique, multi characteristics data was analyzed by utility concept. The results indicate that the best level of control factors paid their own 
contribution for compressive strength at various elevated temperatures. The cement content was found to be the most influencing parameter followed by fine aggregate content and fly ash dosage. The role of chemical admixture dosage was observed to be relatively less marked on the residual compressive strength of high performance concrete. The confirmation tests corroborated the theoretical optimum test conditions [8].

Tanyildizi and Coskun [9] adopted Taguchi approach with an L16 $\left(4^{5}\right)$ to reduce the numbers of experiment. Two control factors (percentage of silica fume and heating degree) for this study were used. The level of importance of these parameters on compressive and splitting tensile strength was determined by using analysis of variance (ANOVA) method. They concluded that the Signal-to-Noise $\operatorname{ratio}(\mathrm{S} / \mathrm{N})$, the optimum parameters for the compressive and splitting tensile strength were obtained from specimens containing $20 \%$ silica fume and $20{ }^{\circ} \mathrm{C}$. Based on ANOVA and F-test, the most effective parameters on the compressive and splitting tensile strength were found as heating degree and silica fume, respectively [9].

Maya and Nivin [10-11] used a statistical method for optimizing the experimental procedure called BoxBehnken. Design Box-Behnken Design was used for minimizing the number of experiments that needs to be carried out. It's a kind of Response surface methodology which is a collection of mathematical and statistical techniques useful for the modeling and analysis of problems in which a response of interest is influenced by several variables. BoxBehnken is a spherical, revolving design viewed as a cube, it consists of a central point and the middle points of the edges. Its design does not contain any points at the vertices of the cubic region created by the upper and lower limits for each variable; which means the reduced number of required runs. The low, middle, and high levels of each variable were designated as $-1,0$, and +1 respectively. It is a second-order designs based on threelevel incomplete factorial designs. And the analysis of the same was carried out using ANOVA. Accordingly, the model prepared for the same was checked correlation between the experimental and predicted values. Box-Behnken design also proved to an economical way of obtaining the maximum amount of information in a short period of time and with the fewest number of experiments. The strong agreement between the yields predicted by the final quadratic model and the experimental results indicate that the accuracy and general ability of the polynomial model are satisfactory [10].

Therefore, the present paper aims at optimizing the various input process parameters for post-fire residual properties of high performance concrete. Further, no technology tables or charts were available for post-fire residual properties of high performance concrete, it is imperative to develop a suitable technology guideline for optimum performance concrete. Volume fraction, age time, and post-heat temperature are considered as input concrete parameters. The process performances such as compressive strength, static elastic modules, flexural strength, ultrasonic pulse velocity, dynamic elastic modulus, Abrasion wear were evaluated.

\section{Experimental details}

\subsection{Procedure}

\subsection{Material Properties}

Alkali resistant fiber glass mesh was used for reinforcing walls of the EPS hollow blocks and the control ones. The GFRP mesh was imported from Italy. Twenty - five different concrete mixes having different amounts of reinforcement, $0.885,1.2,2.22,3.54$, in addition to control sample without fiber were casted in molds made from aluminum to form prisms with dimensions $60 \times 60 \times 300 \mathrm{~mm}$. Steel fibers(12.5 mm long and $0.2 \mathrm{~mm}$ 
diameter) at a concentration of $6.2 \%$ of concrete weight. In addition, glass, polypropylene and basalt fibers were also added to enhance the high temperature properties of concrete to yield concentration.

\subsection{High Temperature Test.}

The specimens were kept covered in a controlled chamber at $20 \pm 2{ }^{\circ} \mathrm{C}$ for $24 \mathrm{~h}$ until demoulding. Thereafter, specimens were placed in water at $20{ }^{\circ} \mathrm{C}$ and $60 \% \mathrm{RH}$ until the 7 th, 28 , and $56^{\text {th }}$ days. Later, the specimens were placed in an electric furnace in which temperature is increased to the desired temperatures at a rate of $5^{\circ} \mathrm{C} / \mathrm{min}$, and they were kept at the tested temperature for $3 \mathrm{~h}$. Then, the power was turn off and the specimens were remained until the furnace cooled down to room temperature to avoid thermal cracking. During the heating period moisture in the test specimens was allowed to escape freely. The applied heating curve (Fig. 1 and Fig.2) was not the standard fire timetemperature curve but a heating-cooling cycle was close to RILEM recommendations [12]. The test specimens were subjected to 200,400 , and $800{ }^{\circ} \mathrm{C}$, and the variation of static properties (compressive strength, flexural strength, static modulus of elasticity) as well as dynamic properties (dynamic modulus of elasticity and ultrasonic pulse velocity ) in addition to abrasion wear as expressed by mass loss \% were determined for both reinforced and control prisms.

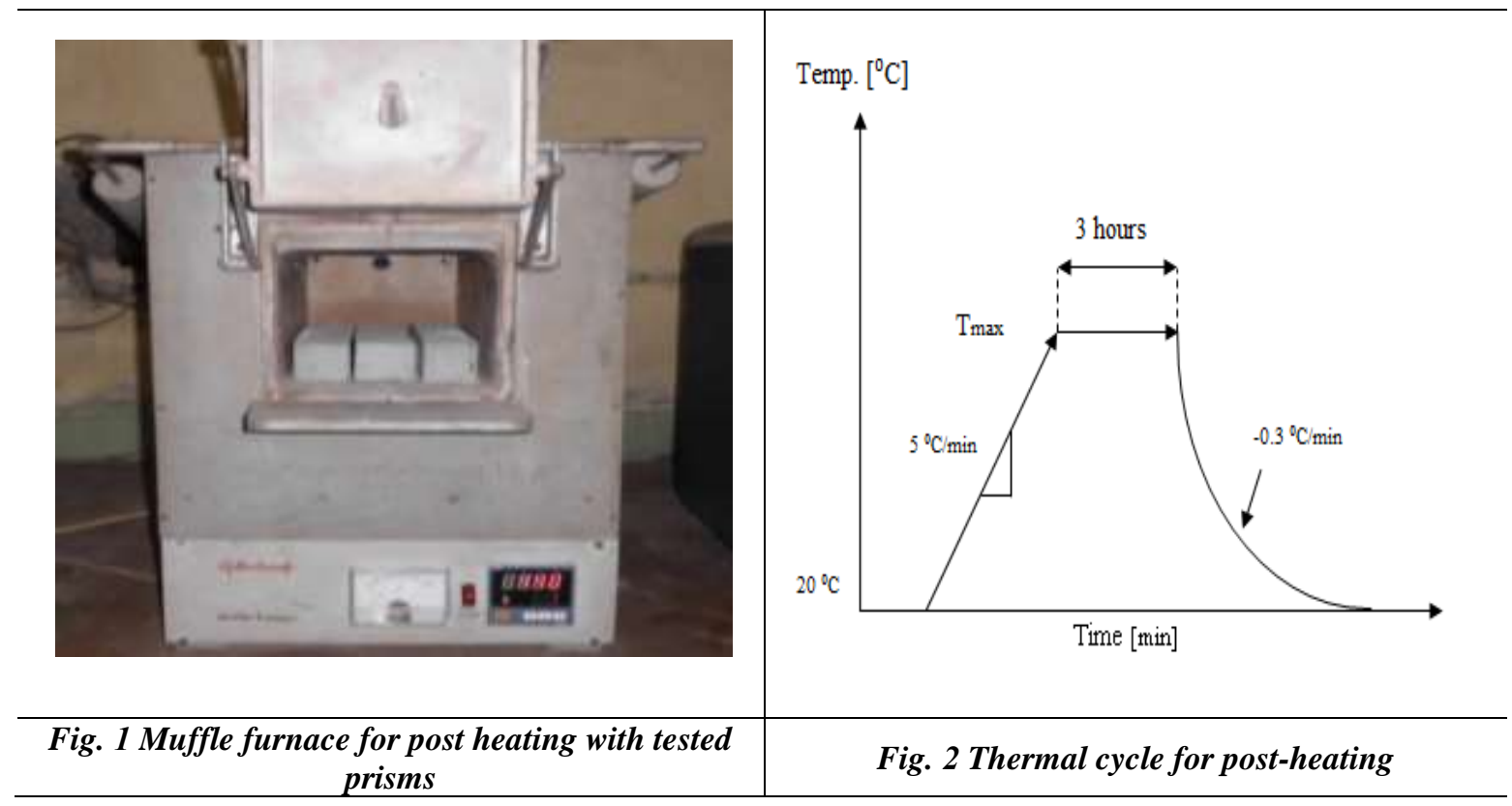

\section{Testing}

\subsection{Compressive and flexural strength test}

Compressive and flexural strength were evaluated via compression cylinders (75 mm dia.x150mm height) and threepoint bending (prisms: 60x60×300 mm) tests. Carried out on: BELJLNG SINOFOUND Co. LTD., Servo Universal Testing Machine, Model WAW-600, SR.
No. 11-108 EXW DATE 2011 YO2M. The machine has a wide range of displacement rates up to $100 \mathrm{~mm} / \mathrm{s}$. However, all the tests of the present work were carried out at a constant displacement rate of 0.5 $\mathrm{mm} / \mathrm{s}$. the static modulus of elasticity, Es, was calculated directly from $3 \mathrm{~Pb}$ test by the Eq. [13].

$$
E_{s}=\frac{S^{3} \Delta P}{4 \mathrm{wB}^{3} \Delta \delta}
$$


Where s, W, and B are the span length, specimen widths and sample thickness, respectively; $\Delta \mathrm{P}$ and $\Delta \delta$ are the load increment and deflection increments measured from the initial portion (linear straight part of the load-deflection curves).

\subsection{Ultrasonic non-destructive testing (USNDT)}

In the present work, the 58E4900UPV tester is used for quality control and inspection of concrete. It measures the transit time of ultrasonic pulses through concrete for inspection of new and old structure, slabs, columns, walls, fire damaged areas precast and prestressed beams, cylinders and other concrete forms. Combined with an oscilloscope can identify honeycombs, voids, cracks and other non-homogeneous conditions in concrete. Description: Hand held light instrument, battery operated, microprocessor incorporated supplied with two $54 \mathrm{kHz}$ transducer (transmitter and receiver) calibration rod, $250 \mathrm{~mm}$ of coupling agent. The meter can also be used with low and high frequency transducer. The tester can determine the Pulse velocity and Dynamic modulus of elasticity.

\subsection{Abrasion Resistance Test}

Cubic samples of $71 \pm 1.5 \mathrm{~mm}$ were used for the determination of abrasion resistance according standard specifications ASTM C779. Many other researchers used this method and obtained reliable results [14-17]. The abrasion system had a steel disk, with a diameter of $750 \mathrm{~mm}$ and rotating speed of $30 \pm 1$ cycle/min, a counter and a lever, which could apply $300 \pm 3 \mathrm{~N}$ on the specimens. In the test procedure, $20 \pm 0.5 \mathrm{~g}$ of abrasion dust was spread on the disk, the specimens were then placed, the load was applied to the specimen and the disk was rotated for 15 minutes. After that, the surfaces of the disk and the sample were cleaned. And the weight decrease was measured due to abrasion. Abrasive dust used in this test was corundum (crystalline AI2O3).

\section{Design of experiments}

Design of experiments (DOE) is a structured, organized method for determining the relationship between factors which affect the process and the output of that process. The Taguchi technique is a powerful tool for the design of high quality systems [18]. Taguchi parameter design can optimize the performance characteristics through the setting of design parameters and reduce the sensitivity of the system performance to the source of variation. The first step in Taguchi's statistical design is the selection of levels and their factors. In the present research, Fiber volume fraction $\mathrm{V}_{\mathrm{f}} \%$, Age time, days and Post-heat temp., ${ }^{\circ} \mathrm{C}$ were considered as input parameters. Based on the available literature and laboratory trials, various levels of these mix parameters were chosen. Table 1 shows the chosen factors and their levels. A standard L25(35) orthogonal array (OA) was selected for the design of experimental trial runs with three factors and five levels, giving rise to a total of twenty five combination of trial mixes as shown in Table 2. The code numbers and actual values of all the three factors are also shown in Table 4. Taguchi used the $\mathrm{S} / \mathrm{N}$ ratio as the quality characteristic of choice. The $\mathrm{S} / \mathrm{N}$ ratio is used as a measurable value instead of the standard deviation because, as the mean decreases, the standard deviation also decreases, and vice versa $[19,20]$. By comparing the $\mathrm{S} / \mathrm{N}$ ratio of the observed values, the optimal combination levels of post-fire parameters were determined. Each experiment is repeated three times to reduce the influence of the uncontrolled factors (noise factors). The quality values (yi) of threerepeated numbers are transformed into the $\mathrm{S} / \mathrm{N}$ ratio $(\eta)$ via the relation:

Larger the better $\mathrm{S} / \mathrm{N}(\mathrm{db})=-10 *$

$\log _{10}\left(\frac{1}{n} \sum_{\mathrm{i}=1}^{\mathrm{n}} \frac{1}{\mathrm{y}_{\mathrm{i}}^{2}}\right)$ 
smaller the better $\mathrm{S} / \mathrm{N}(\mathrm{db})=-10 *$

$$
\log \left[\frac{1}{3}\right] \sum_{\mathrm{i}=1}^{3} \mathrm{y}_{\mathrm{i}}^{2}
$$

Where the quality value with larger-thebetter style has been assumed for all of the measured quality parameters except for abrasion wear. A control parameter with the largest effect means that it has the most significant influence on the concrete quality. The analysis of variance (ANOVA) is used to discuss the relative importance of all control parameters on the concrete quality and to determine which control parameter has the most significant effect. The predicted value of the $\mathrm{S} / \mathrm{N}$ ratio

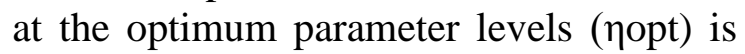
calculated by using the following formula:

$\eta_{\text {opt }}=\bar{\eta}+\sum_{\mathrm{i}=1}^{\mathrm{k}}\left(\eta_{\mathrm{mi}}-\bar{\eta}\right)$

Where $\mathrm{k}$ is the number of control parameters, $h$ is the overall mean value of the 25 experiments, and $\eta \mathrm{mi}$ is the average $\mathrm{S} / \mathrm{N}$ ratio for $\mathrm{i}$ the control parameter corresponding to the optimum parameter level.

\section{Analysis of experimental results and discussion}

\subsection{Effect of post fire parameters} on the compressive strength (MPa)

Figure 3 represents the Main effects plot (data means) for the compressive strength against volume fraction, age time, and post-heat temperature. It can be seen that the compressive strength generally increases with increasing volume fraction and age time. This reflects the mechanical adhesion performance of shape fibers within the concrete matrix that delays cracking limitation and propagation. Such effect is intensified at longer age time which enabled concrete to be fully hydrated and to keep interpores water at their lowest levels.

The response table of the $\mathrm{S} / \mathrm{N}$ ratio for the compressive strength (Table 3) indicates that the post-heat temperature is the most significant parameter affecting the compressive strength $(60.16 \%$ contribution), followed by the volume fraction (25.8\% contribution). However, the other parameter age time has no significant effect ( $13.96 \%$ contribution). The surface plot of the compressive strength data as affected by the input parameters are given in Figs.4. Post-heat temperature has a much pronounced effect on fc followed by Vf and the age time. This is quite true at low as well as high values of Vf. Also, the high level of Vf still has a beneficial impact to minimize the catastrophic failure of concrete when exposed to high temperature. At temperature beyond $400 \mathrm{oC}$, concrete begins to lose its strength as a result of the immediate expansions that take place during the expansion of silica fumes used in the tested concrete. Although SF addition increased the initial strength of concrete, considerable loss in fc when exposed to high temperature is noticed. The loss in fc was about $32 \%$ of the corresponding initial strength when the concrete was exposed to $400 \mathrm{oC}$. As the temperature was increased to $800 \mathrm{oC}$, the loss reached $86 \%$. These results agreed well with that obtained by Husen[21]

Table 1 Experimental parameters and levels

\begin{tabular}{|c|c|c|c|c|c|c|c|}
\hline \multirow[t]{2}{*}{ Factor } & \multirow[t]{2}{*}{ Symbol } & \multicolumn{5}{|c|}{ Levels } & \multirow{5}{*}{\begin{tabular}{|l|}
\multicolumn{2}{|c|}{ Output parameters } \\
Compressive strength, static \\
elastic modules, flexural \\
strength, ultrasonic pulse \\
velocity, dynamic elastic
\end{tabular}} \\
\hline & & 1 & 2 & 3 & 4 & 5 & \\
\hline $\begin{array}{l}\text { a)Fiber volume } \\
\text { fraction } V_{f} \%\end{array}$ & $\mathbf{V}_{\mathbf{f}}$ & $\mathbf{0}$ & 0.88 & 1.2 & 2.22 & 3.54 & \\
\hline b) Age time, days & $t$ & 7 & 28 & 56 & 7 & 28 & \\
\hline c) Post-heat temp., ${ }^{\circ} \mathrm{C}$ & $\mathbf{F}_{T}$ & 25 & 200 & 400 & 800 & 25 & \\
\hline
\end{tabular}


Table 2 L25 matrix for the experiments and experimental results

\begin{tabular}{|c|c|c|c|c|c|c|c|c|c|}
\hline \multirow[b]{2}{*}{ Expno. } & \multicolumn{3}{|c|}{ Input parameters } & \multicolumn{6}{|c|}{ Experimental results } \\
\hline & a) $V_{f} \%$ & $\begin{array}{l}\text { b) Age } \\
\text { time, } \\
\text { days }\end{array}$ & $\begin{array}{l}\text { c) Post - } \\
\text { heat } \\
\text { temp. } \\
{ }^{\circ} \mathrm{C} \\
\end{array}$ & $\begin{array}{l}\text { Compressive } \\
\text { strength, } \\
\text { MPa }\end{array}$ & $\begin{array}{c}\text { E.Static, } \\
\text { GPa }\end{array}$ & $\begin{array}{l}\text { Flexural } \\
\text { str., MPa }\end{array}$ & $\begin{array}{l}\text { UPV } \\
\mathbf{K m} / \mathbf{s}\end{array}$ & $\begin{array}{l}\text { E. dynamic } \\
\text { GPa }\end{array}$ & $\begin{array}{c}\text { Abrasion } \\
\text { wear, wt. } \\
\text { loss \% }\end{array}$ \\
\hline 1 & $\mathbf{0}$ & 7 & 25 & 50 & 23 & 10.97 & 3.201 & 20.89 & 7.05 \\
\hline 2 & $\mathbf{0}$ & 28 & 200 & 55 & 27 & 12.07 & 3.307 & 22.22 & 5.55 \\
\hline 3 & $\mathbf{0}$ & 56 & 400 & 40 & 25 & 9.83 & 2.630 & 14.11 & 3.98 \\
\hline 4 & $\mathbf{0}$ & 7 & 800 & 0.85 & 7 & 0.645 & 0.514 & 0.51 & 8.07 \\
\hline 5 & $\mathbf{0}$ & 28 & 25 & 60 & 26 & 11.45 & 3.302 & 22.22 & 6.57 \\
\hline 6 & 0.885 & 7 & 200 & 66 & 32 & 19.38 & 4.281 & 37.38 & 4.06 \\
\hline 7 & 0.885 & 28 & 400 & 86 & 29 & 16.03 & 4.691 & 44.89 & 3.32 \\
\hline 8 & 0.885 & 56 & 800 & 30 & 15 & 10.13 & 2.06 & 8.66 & 2.06 \\
\hline 9 & 0.885 & 7 & 25 & 71 & 35 & 18.58 & 4.213 & 36 & 4.9 \\
\hline 10 & $\begin{array}{l}0.885 \\
\end{array}$ & 28 & 25 & 82 & 37 & 19.01 & 4.727 & 45.6 & 4.24 \\
\hline 11 & 1.2 & 7 & 400 & 50 & 28 & 24.24 & 3.91 & 34.14 & 2.16 \\
\hline 12 & 1.2 & 28 & 800 & 40 & 13 & 8.97 & 2.19 & 10.18 & 1.36 \\
\hline 13 & 1.2 & 56 & 25 & 96 & 43 & 29.17 & 4.801 & 49.37 & 2.39 \\
\hline 14 & 1.2 & 7 & 25 & 83 & 36 & 20.10 & 4.305 & 41.5 & \begin{tabular}{|c|}
3.33 \\
\end{tabular} \\
\hline 15 & 1.2 & 28 & 200 & 97 & 35 & 28.44 & 4.803 & 49.37 & 2.04 \\
\hline 16 & 2.22 & 7 & 800 & 11.6 & 13 & 8.56 & 1.95 & 8.92 & 1.97 \\
\hline 17 & 2.22 & 28 & 25 & 99 & 40 & 30.47 & 4.803 & 51.72 & 2.47 \\
\hline 18 & 2.22 & 56 & 25 & 100 & 43 & 35.05 & 4.831 & 52.37 & 1.66 \\
\hline 19 & 2.22 & 7 & 200 & 80 & 34 & 32.21 & 4.290 & 43.15 & 2.42 \\
\hline 20 & 3.54 & 28 & 400 & 100 & 30 & 28.37 & 4.77 & 51.07 & 1.6 \\
\hline 21 & 3.54 & 7 & 25 & 92 & 38 & 30.48 & 4.214 & 43.96 & 1.94 \\
\hline 22 & 3.54 & 28 & 25 & 101 & 43 & 35.76 & 5.09 & $\begin{array}{l}60.8 \\
\end{array}$ & 1.88 \\
\hline 23 & 3.54 & 56 & 200 & 108 & 41 & 36.05 & 5.09 & 60.8 & 0.93 \\
\hline 24 & 3.54 & 7 & 400 & 53 & 23 & 29.12 & 4.005 & 39.18 & 1.63 \\
\hline 25 & 3.54 & 28 & 800 & 46 & 16 & 14.26 & 2.17 & 11.05 & 1.06 \\
\hline
\end{tabular}

Table 3 Analysis of the compressive strength (MPa) results

\begin{tabular}{|c|c|c|c|c|c|c|c|c|}
\hline \multirow{2}{*}{ Parameter } & \multicolumn{5}{|c|}{ Average $\eta(S)$ by factor level $(\mathrm{dB})$} & \multirow[t]{2}{*}{ Delta } & \multirow[t]{2}{*}{ Rank } & \multirow[t]{2}{*}{ Contribution \% } \\
\hline & 1 & 2 & 3 & 4 & 5 & & & \\
\hline $\mathrm{V}_{\mathrm{f}} \%$ & 27.00 & $35.96^{*}$ & $36.85^{*}$ & $35.85^{*}$ & 37.55 & 10.56 & 2 & 25.8 \\
\hline Age time & 31.15 & 37.24 & 36.38 & 31.15 & 37.24 & 6.09 & 3 & 13.96 \\
\hline Post heat temp. & $38.21^{*}$ & 37.93 & 35.84 & 22.94 & $38.21^{*}$ & 15.27 & 1 & 60.16 \\
\hline
\end{tabular}

* Optimum level

Overall mean $=32.237 \mathrm{~dB}$

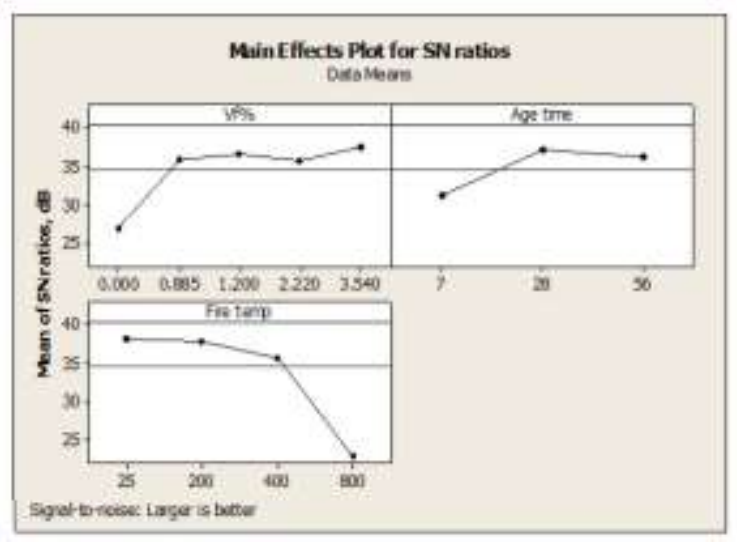

Overall mean $=34.895 \mathrm{MPa}$

Fig. 3 Main effects plot (data means) for the compressive strength

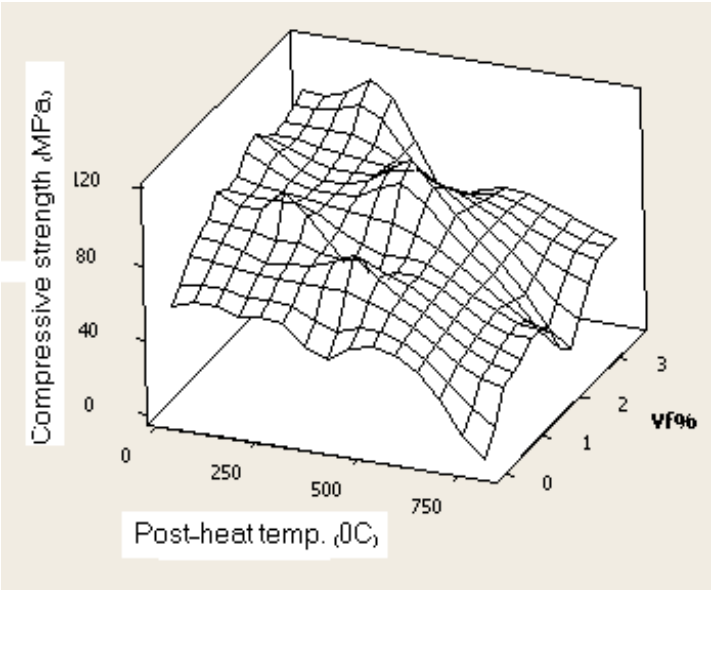

Fig. 4 Dependence of compressive strength on response surface for post-heat temperature and fiber volume fraction 


\subsection{Effect of post fire parameters on the static elastic modules}

From Fig. 5 and Table 4 it is clear that the post-heat temperature is the most significant parameter affecting the static elastic modules $(77.35 \%$ contribution), followed by volume fraction $(16.04 \%$ contribution). However, the other has no significant effect on the static elastic modules $(6.59 \%$ contribution). It can be noticed that, with the increase of volume fraction and age time, the formed static elastic modules for static elastic modulus $\mathrm{E}_{\mathrm{s}}$, Figs. 6. Post-heat temperature effect on $E_{s}$ is quite similar to $f_{c}$ although the rate of decrease in $\mathrm{E}_{\mathrm{s}}$ with temperature is higher compared with $\mathrm{f}_{\mathrm{c}}$.

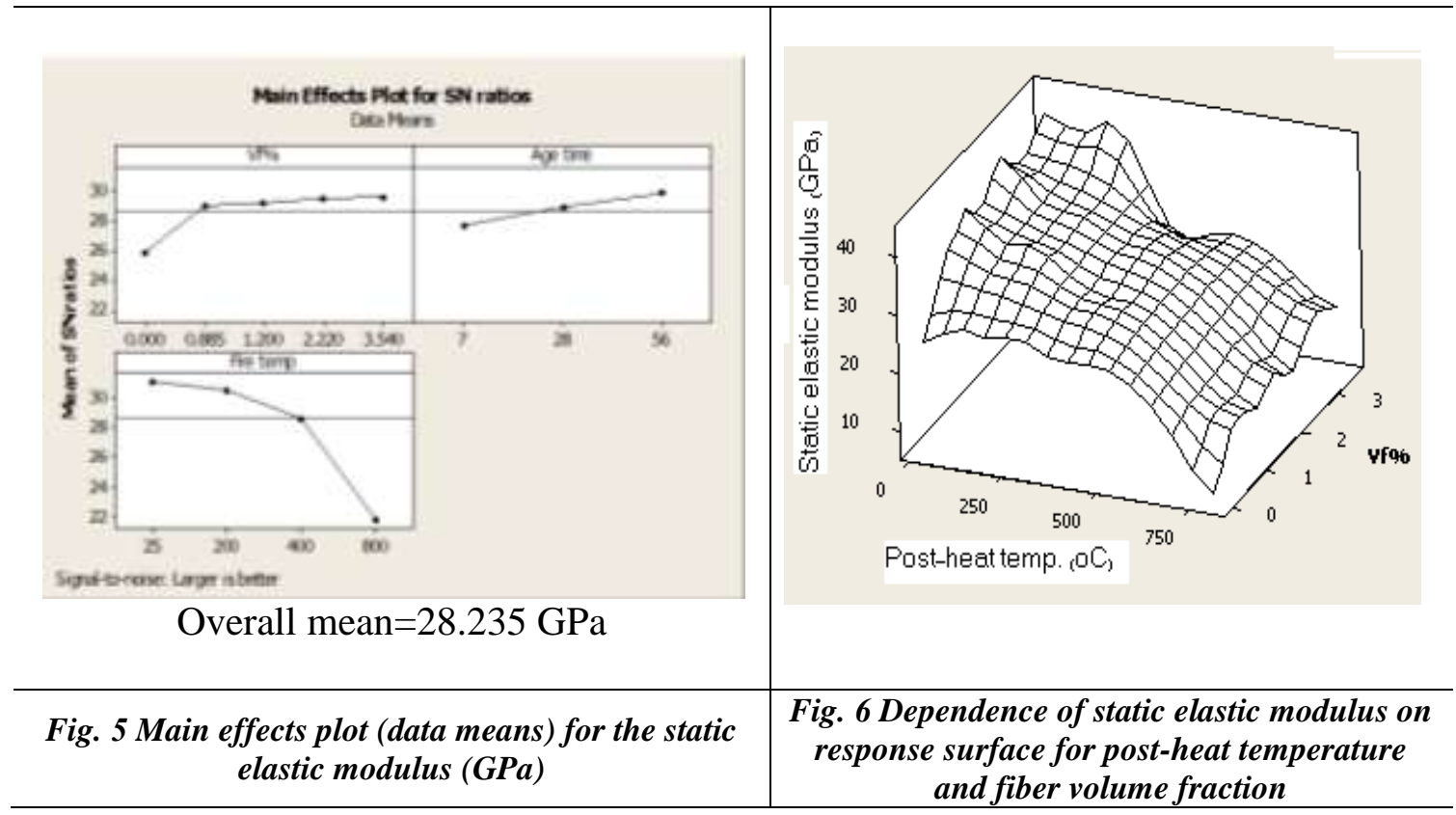

Table 4 Analysis of the static elastic modules (GPa) results

\begin{tabular}{|c|c|c|c|c|c|c|c|c|}
\hline \multirow{2}{*}{ Parameter } & \multicolumn{5}{|c|}{ Average $\eta(S)$ by factor level (dB) } & \multirow[t]{2}{*}{ Delta } & \multirow[t]{2}{*}{ Rank } & \multirow{2}{*}{$\begin{array}{c}\text { Contributio } \\
\text { n } \%\end{array}$} \\
\hline & 1 & 2 & 3 & 4 & 5 & & & \\
\hline $\mathbf{V}_{\mathrm{f}} \%$ & 25.80 & 29.02 & 29.18 & 29.43* & $\begin{array}{c}29.5 \\
7\end{array}$ & 3.76 & 2 & 16.04 \\
\hline Age time & 27.69 & 28.90 & $29.82^{*}$ & 27.69 & $\begin{array}{c}28.9 \\
0\end{array}$ & 2.12 & 3 & 6.59 \\
\hline $\begin{array}{l}\text { Post heat } \\
\text { temp. }\end{array}$ & $31.06^{*}$ & $30.50 *$ & 28.59 & 21.81 & $\begin{array}{c}31.0 \\
6 *\end{array}$ & 9.24 & 1 & 77.35 \\
\hline
\end{tabular}

*Optimum level Overall mean $=28.183 \mathrm{~dB}$

\subsection{Effect of post fire parameters on the flexural strength}

Figure 7 displays the main effects of the post fire parameters on the mean value for the flexural strength. As post-heat temperature increases, while increasing the volume fraction causes increasing flexural strength increasing the age time increases the resultant flexural strength. Table 5 indicates that the volume fraction has the greatest effect $(53.03 \%$ contribution) on the flexural strength. The effect of the post-heat temperature has the second largest effect among the other factors ( $40.66 \%$ contribution), and then age time ( $6.31 \%$ contribution). For flexural strength, Fig. 8. the higher the post- heat temperature, the lower will be the flexural strength. Such effect is remarkable at the high level of $V_{f}$. 


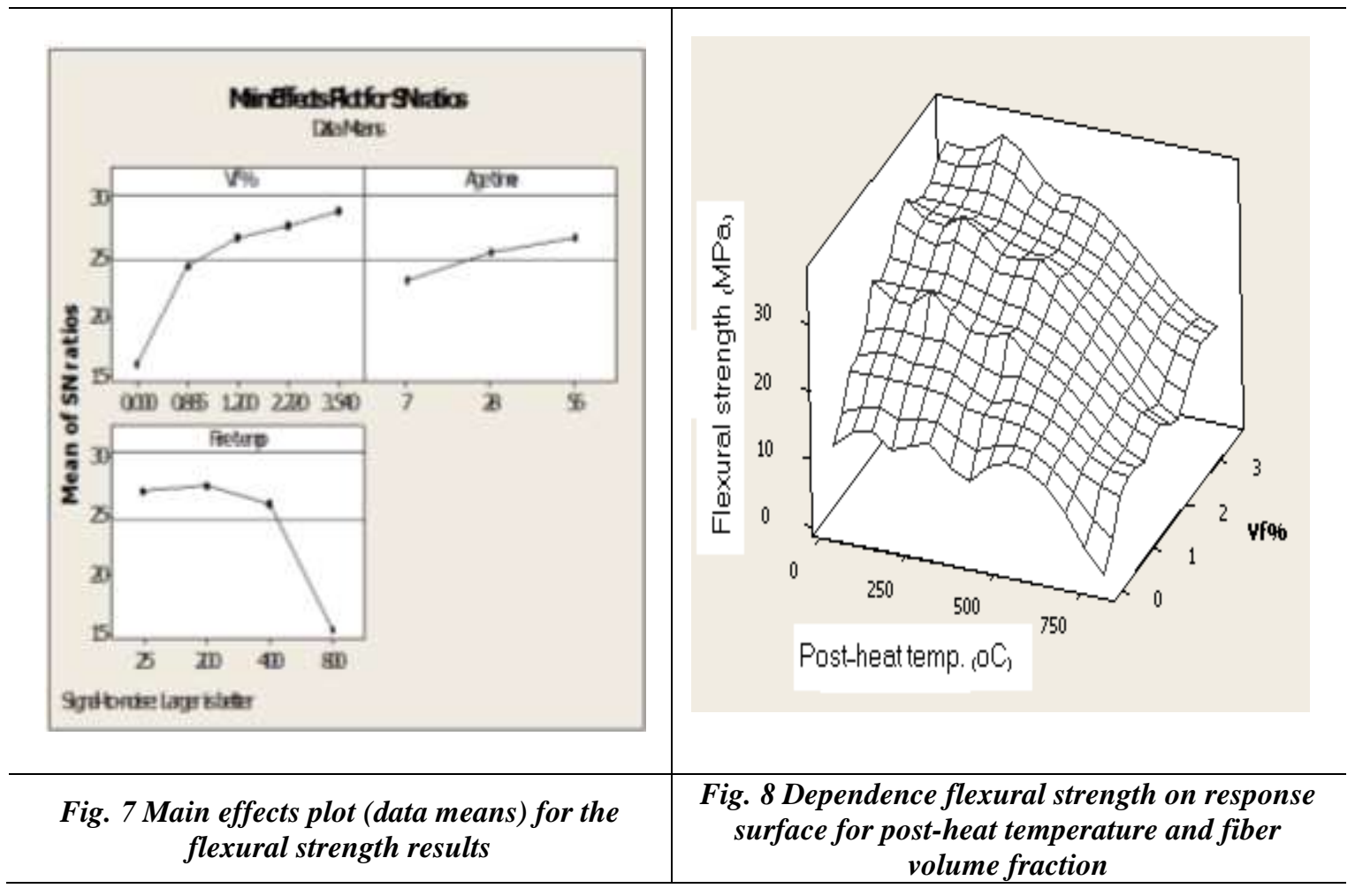

Table 5 Analysis of the flexural strength results

\begin{tabular}{|c|c|c|c|c|c|c|c|c|}
\hline \multirow[t]{2}{*}{ Parameter } & \multicolumn{5}{|c|}{ Average $\eta(S)$ by factor level (dB) } & \multirow[t]{2}{*}{ Delta } & \multirow[t]{2}{*}{ Rank } & \multirow[t]{2}{*}{ Contribution \% } \\
\hline & 1 & 2 & 3 & 4 & 5 & & & \\
\hline $\mathbf{V}_{\mathrm{f}} \%$ & 15.93 & 24.18 & 26.56 & 27.69 & 28.85 & 12.92 & 1 & 53.03 \\
\hline Age time & 22.97 & 25.35 & 26.58 & 22.97 & 25.35 & 3.61 & 3 & 6.31 \\
\hline Post heat temp. & 27.12 & 27.55 & 26.00 & 15.42 & 27.12 & 12.13 & 2 & 40.66 \\
\hline
\end{tabular}

*optimum level Overall mean $=22 \mathrm{~dB}$

\subsection{Effect of post fire parameters on the ultrasonic pulse velocity}

From Fig. 9 and Table 6 it is clear that the post-heat temperature is the most significant parameter affecting the ultrasonic pulse velocity $(70.88 \%$ contribution), followed by volume fraction ( $24.86 \%$ contribution). However, the other has no significant effect on the ultrasonic pulse velocity ( $4.23 \%$ contribution). Also, Figs .10and11. Are shown the higher the Vf- values, the greater will be UPV simply because of the accelerating effect of fibers for sound waves to pass through without attenuation. Such results reflects the good dispersion of fibers in the matrix with minimum defect densities (cracks , fussers, voids .....etc ).This was assisted by SEM micrographs shown in Fig . 12. As for the post heat temperature UPV decreases monotonically with temperature. For both low and high level of $V_{f}$. Such effect as the attributed to the existence of various fissures, microcracks, as well as fiber Debonding associated with high temperature exposure. Fig. 10 and 11 shows the results obtained from the UPV measurements of specimens subjected to different high temperatures. Each data point represents the average of three measurements. It is shown in the Fig. 11 that the UPV decreases with an increasing temperature, and there is a notable reduction in UPV shortly after the specimens are subjected to elevated temperature over $400^{\circ} \mathrm{C}$. It is obvious that the transmission of pulse waves through a concrete mass is highly influenced by the microcracking of concrete. Thus, the decrease impulse velocity with increasing temperature is a sensitive measure of the 
progress of cracking in the material. Yang et al. also found similar results in their experiments [22]. It can be concluded that the addition of PP fibers had negative effect on UPV of LWHSC when exposed to high temperatures. When the temperature was raised to above the melting point $\left(162^{\circ} \mathrm{C}\right)$ of PP fibers more randomly distributed pathways or voids in prisms were generated [23]. In addition, thermal expansion and dehydration of the concrete due to high temperature might lead to the formation of fissures in the concrete. Because of more fissures, cracks or micro pathways in concrete pulse velocity delays to reach from transmitter to receiver.

Table 6 Analysis of the ultrasonic pulse velocity

\begin{tabular}{|c|c|c|c|c|c|c|c|c|}
\hline \multirow{2}{*}{ Parameter } & \multicolumn{5}{|c|}{ Average $\eta(S)$ by factor level $(\mathrm{dB})$} & \multirow[t]{2}{*}{ Delta } & \multirow{2}{*}{ Rank } & \multirow[t]{2}{*}{ Contribution \% } \\
\hline & 1 & 2 & 3 & 4 & 5 & & & \\
\hline$V_{\mathrm{f}} \%$ & 6.698 & 11.663 & 11.718 & 11.866 & 11.909 & 5.211 & 2 & 24.86 \\
\hline Age time & 9.697 & 11.618 & 11.224 & 9.697 & 11.618 & 1.922 & 3 & 4.23 \\
\hline Post heat temp. & 12.671 & 12.687 & 11.858 & 3.967 & 12.671 & 8.720 & 1 & 70.88 \\
\hline
\end{tabular}

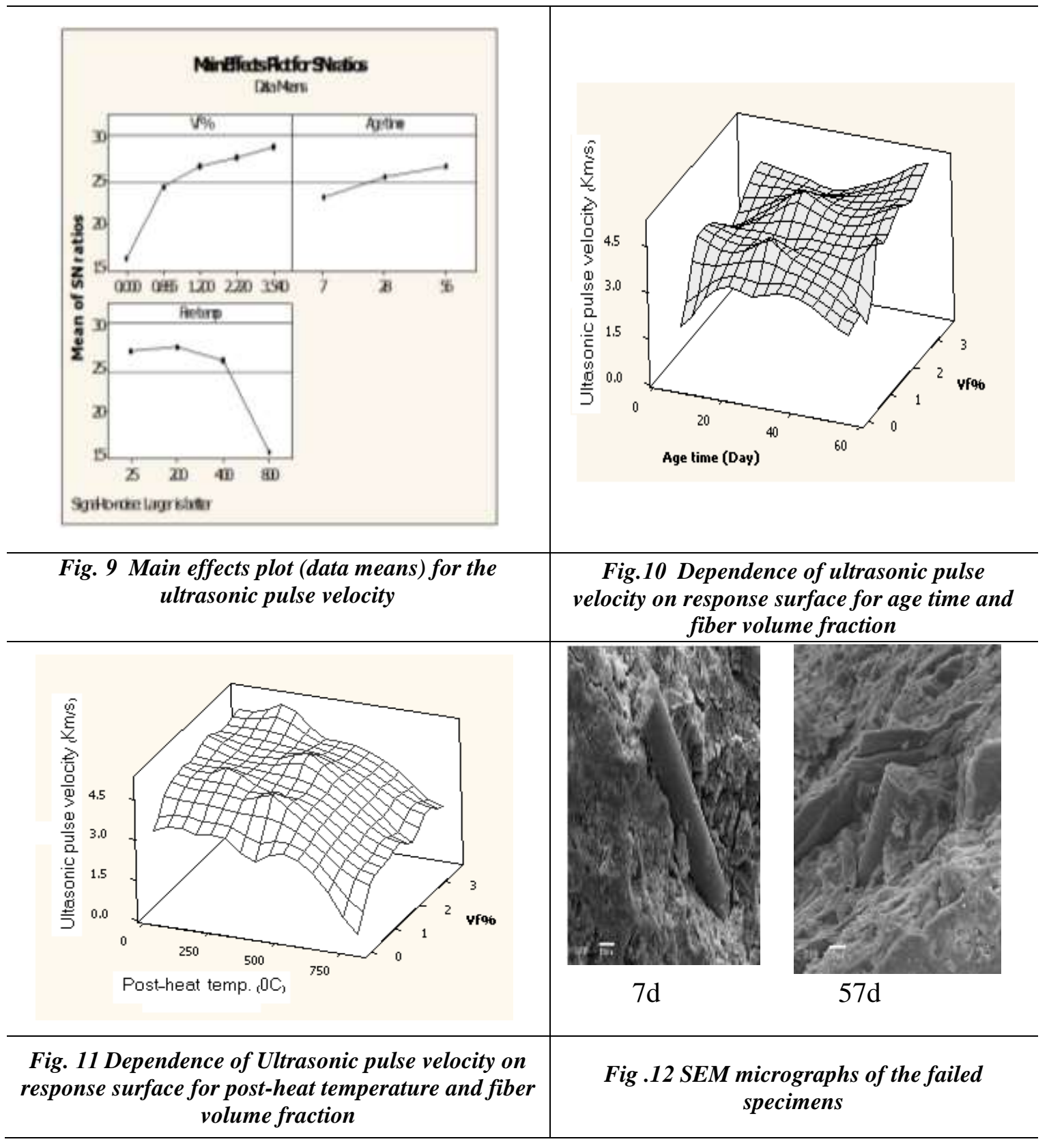


5.5 Effect of post fire parameters on the of the dynamic elastic modulus

Figure 13 shows the main effects of the post fire parameters on the mean of the dynamic elastic modulus. It can be noticed that, with the increase of both volume fraction and age time, the dynamic elastic modulus increases. It is also clear that the increase of the post-heat temperature (fire temp.) decreases the dynamic elastic modulus. From Fig. 13 and Table 7 it is clear that the post-heat temperature is the most significant parameter affecting the ultrasonic pulse velocity $(61.31 \%$ contribution), followed by volume fraction (33.10\% contribution). However, the other has no significant effect on the ultrasonic pulse velocity (5.59\% contribution). Also, Fig 14. As a general rule, $E_{d}$ decreases with temperature simply due to the softening processes of the fibers and the hair fissures resulting from high temperature. However, the rate of such decrease depends upon $V_{f}$. The higher the $V_{f}$-value, the lower will be the rate of decrease in $E_{d}$.

\subsection{Effect of post fire parameters on the abrasion wear (wt. loss \%)}

Figure 15 displays the main effects of the post fire parameters on the mean value for the abrasion wear. As post-heat temperature increases, the resultant abrasions wear increases. While increasing the volume fraction causes increasing abrasion wear. Increasing the age time increases the resultant abrasion wear. Table 8 indicates that the volume fraction has the greatest effect $(79.75 \%$ contribution) on the abrasion wear. The effect of the age time has the second largest effect among the other factors (13.45\% contribution), and then the postheat temperature $(6.8 \%$ contribution). Also, for abrasion wear Concrete and reinforced concrete structures endure variable and repeated loads, which may, in the end, induce material fatigue. Fatigue may, in turn, generate a progressive deterioration of the material up to failure, especially under applied complex mechanical loading cycles. Highperformance of concrete materials, then, requires durability and resistance. This resistance can be expressed as the friction or abrasion bearing capacity of a material. Abrasion resistance is studied experimentally through the weight (mass) loss of specimens resulting from abrasion testing.. The tested specimens are approximately the same weight and are subjected to the same abrasive load. , Fig. 16 increasing age time decreases considerably the abrasion specially at low level of $\mathrm{V}_{\mathrm{f}}$ since at high $\mathrm{V}_{\mathrm{f}}$-value the abrasion wear is quite small.

Table 7 Analysis of the dynamic elastic modulus

\begin{tabular}{|c|c|c|c|c|c|c|c|c|}
\hline \multirow{2}{*}{ Parameter } & \multicolumn{4}{|c|}{ Average $\eta(S)$ by factor level (dB) } & \multirow{2}{*}{ Delta } & $\begin{array}{c}\text { Ra } \\
\text { nk }\end{array}$ & $\begin{array}{c}\text { Contribution } \\
\%\end{array}$ \\
\cline { 2 - 8 } & 1 & 2 & 3 & 4 & 5 & \multicolumn{2}{|c|}{} \\
\hline$V_{\mathrm{f}} \%$ & 19.48 & 29.51 & 30.23 & 30.91 & 31.39 & 11.91 & 2 & 33.10 \\
\hline Age time & 26.28 & 29.91 & 29.13 & 26.28 & 29.91 & 3.63 & 3 & 5.59 \\
\hline $\begin{array}{c}\text { Post heat } \\
\text { temp. }\end{array}$ & 32.13 & 32.13 & 30.54 & 14.59 & 32.13 & 17.54 & 1 & 61.31 \\
\hline
\end{tabular}




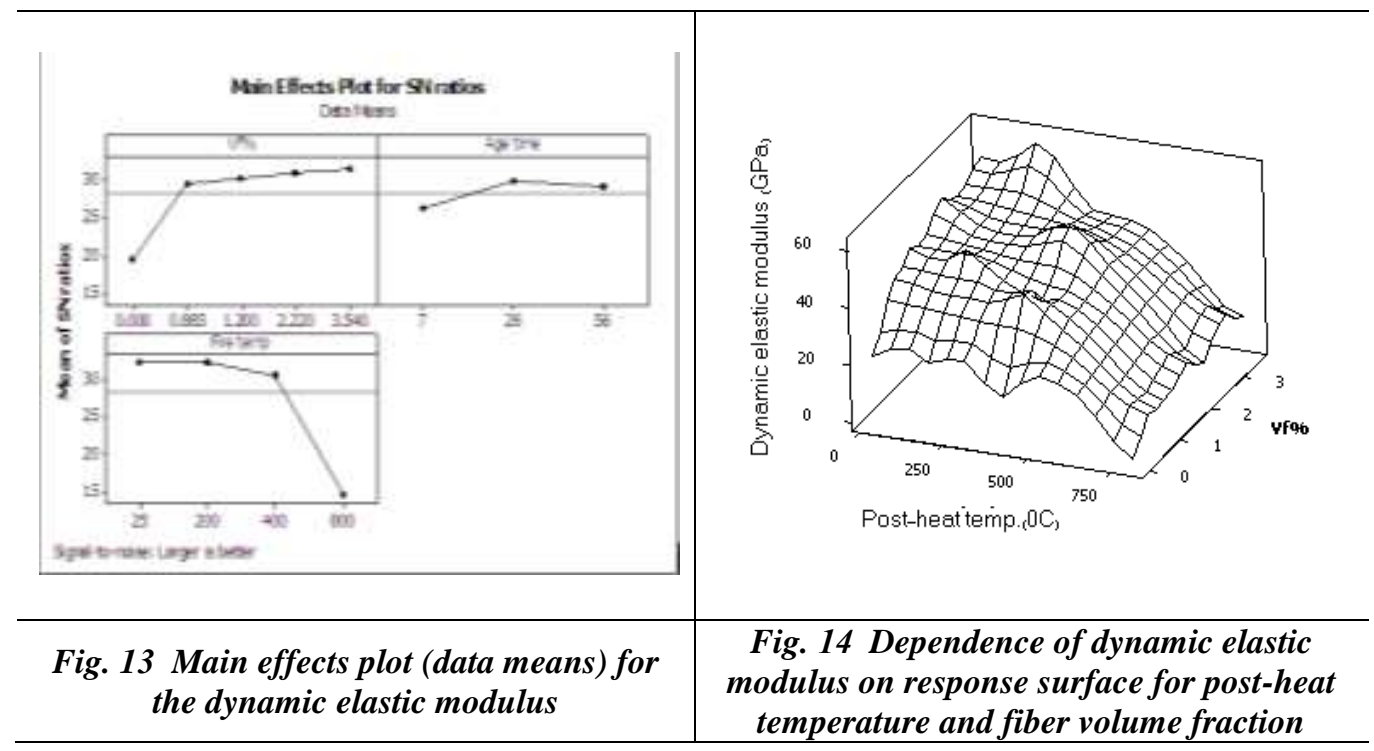

Table 8 Analysis of abrasion wear

\begin{tabular}{|c|c|c|c|c|c|c|c|c|}
\hline \multirow{2}{*}{ Parameter } & \multicolumn{5}{|c|}{ Average $\eta(S)$ by factor level (dB) } & \multirow[t]{2}{*}{ Delta } & \multirow[t]{2}{*}{ Rank } & \multirow[t]{2}{*}{$\begin{array}{c}\text { Contribution } \\
\%\end{array}$} \\
\hline & 1 & 2 & 3 & 4 & 5 & & & \\
\hline$V_{f} \%$ & -15.580 & -11.673 & -6.714 & -5.981 & -3.072 & 12.509 & 1 & 79.75 \\
\hline Age time & -10.492 & -8.056 & -5.923 & -10.492 & -8.056 & 4.569 & 2 & 13.45 \\
\hline $\begin{array}{l}\text { Post heat } \\
\text { temp. }\end{array}$ & -10.074 & -8.688 & -7.487 & -6.696 & $\begin{array}{c}- \\
10.074\end{array}$ & 3.378 & 3 & 6.8 \\
\hline
\end{tabular}

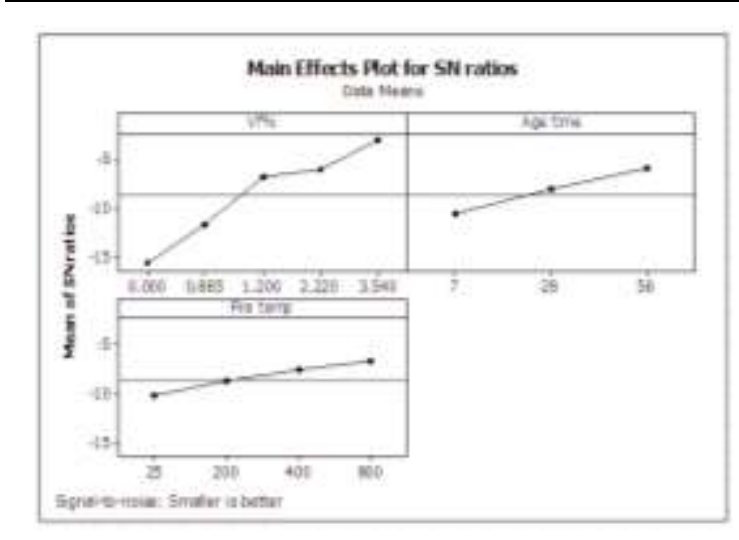

Fig. 15 Main effects plot (data means) for the Abrasion wear

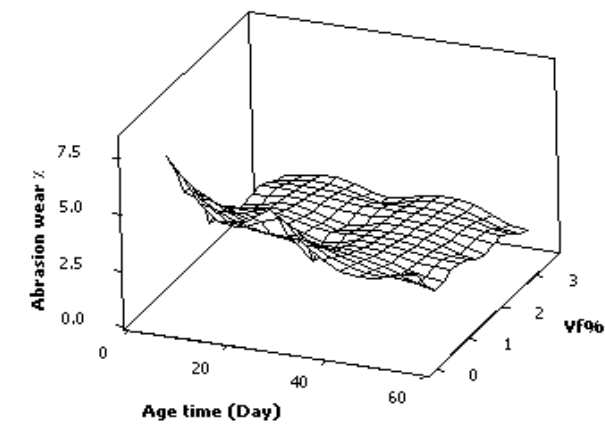

Fig. 16 Dependence of abrasion wear on response surface for age time and fiber volume fraction

\section{Mathematical modeling}

The regression models are very promising for practical applications, such as estimating the observed values and correlated parameters, although the parameters may not be as precise as those produced by the Taguchi method. The models for the quality of post fire were developed to evaluate the relationship of concrete process parameters to compressive strength, static elastic modules, flexural strength, ultrasonic pulse velocity, dynamic elastic modulus, abrasion wear. Through these models, any experimental results of the measured response data with any combination of Post fire process parameters can be estimated. The model has been employed on the basis of experimental results. 
Among several models tested, the exponential model is found to be the bestfit model. If the quadratic model is chosen, the second-order polynomial function that is the most accurate is given. The quadratic model of [24] can be written as:

$$
y=\beta_{0}+\sum_{i=1}^{k} \beta_{i} X_{i}+\sum_{i=1}^{k} \beta_{i j} X^{2}+\sum_{i} \sum_{j} \beta_{i j} X_{i} X_{j}+\varepsilon
$$

The coefficient $\beta_{\mathbf{0}}$ is the free term, the coefficients $B_{\mathbf{i}}$ are the linear terms, the coefficients $\beta_{\mathbf{i j}}$ are the interaction terms, and the coefficients $\beta_{\text {ii }}$ are the quadratic terms.

\subsection{Effect of input parameters on measured properties}

Based on Eq. (5), the effect of input parameters (Table 3.1) on compressive strength, static elastic modulus, flexural strength, ultrasonic pulse velocity, dynamic elastic modulus and abrasion wear have been evaluated by computing the values of various constants using Design Expert software version(6) and the relevant experimental results from Table 4.2. The mathematical model of the parameters can be expressed as follows:

$$
\begin{aligned}
& \boldsymbol{Y}_{\text {comp.st. }}=41.0458+28.1603 V_{f}+1.4045 t-0.0008 F_{T}-5.7555 V_{f}^{2}-0.0237 t^{2}-0.0001 F_{T}^{2}+ \\
& 0.1972 V_{f} * t-0.0078 V_{f} * F_{T}+0.0005 t * F_{T} \\
& \boldsymbol{Y}_{\text {Elastic static }}=25.6045+9.1692 V_{f}+0.1394 t-0.0104 F_{T}-1.7394 V_{f}^{2}-0.0007 t^{2}+0.0215 V_{f} * t- \\
& 0.0029 V_{f} * F_{T} \\
& \boldsymbol{Y}_{\text {Flex.st. }}=8.7754+13.2588 V_{f}+0.0331 t+0.0166 F_{T}-1.9742 V_{f}^{2}+0.0016 t^{2}+0.0125 V_{f} * t- \\
& 0.0032 V_{f} * F_{T}-0.00001 t * F_{T} \\
& \boldsymbol{Y}_{\text {Ultr.Pulse }}=2.93044+1.27802 V_{f}+0.03221 t+0.00161 F_{T}-0.28728 V_{f}^{2}-0.00058 t^{2}-0.00001 F_{T}{ }^{2}+ \\
& 0.00537 V_{f} * t-0.00007 V_{f} * F_{T}+0.0001 t * F_{T} \\
& \boldsymbol{Y}_{\text {Elastic dyn. }}=17.0535+19.5855 V_{f}+0.4533 t-0.0370 F_{T}-3.7323 V_{f}^{2}-0.0083 t^{2}-0.0001 F_{T}^{2}+ \\
& 0.1233 V_{f} * t-0.0083 V_{f} * F_{T}-0.0001 t * F_{T} \\
& \boldsymbol{Y}_{\text {Abrasion wear }}=7.85693-3.54724 V_{f}-0.06332 t-0.00224 F_{T}+0.57172 V_{f}^{2}+0.00029 t^{2}+ \\
& 0.01186 V_{f} * t-0.00027 V_{f} * F_{T}-0.00003 t * F_{T}
\end{aligned}
$$

Where $V_{f}$ is volume fraction $\%, \mathrm{t}$ is age time( days), and $F_{T}$ is post- heat temperature, ${ }^{\circ} \mathrm{C}$.

The values of $\mathrm{R}^{2}$ (coefficient of determination) were $0.932,0.966,0.943$, $0.983,0.924$, and 0.934 for equations 6,7 , $8,9,910$, and 11 respectively. $\mathrm{R}^{2}$ is the correlation measure for testing the goodness of fit of regression equation. A perfect agreement between the observed and predicted values would result in $\mathrm{R}^{2}=1$.

\section{Conclusions}

In this study, the effect of experimental parameters namely fiber value fracture, age time and post fire on compressive strength, static elastic modules, flexural strength, ultrasonic pulse velocity (UPV), dynamic elastic modulus, and abrasion wear are investigated experimentally and statistically Taguchi technique and ANOVA. Specific findings of this research include the followings:

1. This study establishes a procedure for computing the optimum mix conditions for maximum residual compressive strength of high performance concrete exposed to various elevated temperatures The results show that the mix parameters change their influence on the residual compressive strength with the change in temperature of exposure. The most influencing parameter affecting the residual compressive strength of concrete is found to be the post-heat 
temperature with a significant ratio of $60.16 \%$ followed by volume fraction with $25.8 \%$.

2. The overall most influencing parameter for achieving a minimum abrasion wear of heated LWHSC, exposed to any temperature up to $800^{\circ} \mathrm{C}$, is the fiber volume fraction with a significant ratio of $79.75 \%$ followed by age time with ratio of $13.45 \%$. The most significant parameter influencing UPV is found to be the post-heat temperature followed by fiber content with ratios $70.88 \%$ and $24.86 \%$ respectively. These observations can be kept in mind while designing the concrete mixes for structures liable to be exposed to elevated temperatures.

3. The optimal combination of post fire parameters of the current optimal process parameter setting are volume fraction of $2.440 \%$, age time of 56 day, and fire temp. (Post-heat temperature) of $200{ }^{\circ} \mathrm{C}$.

4. The error between the experimental results at the optimum settings and the predicted values for compressive strength, static elastic modules, flexural strength, ultrasonic pulse velocity, dynamic elastic modulus, and abrasion wear lie within $1.910 \%$, $2.2 .97 \%, 0.221 \%, 0.217 \%, 2.903 \%$, $0.996 \%$ respectively. Obviously, this confirms excellent reproducibility of the experimental conclusions.

The research findings along with various mathematical models will provide effective guideline to select parameter settings for achieving desired compressive strength, static elastic modules, flexural strength, ultrasonic pulse velocity, dynamic elastic modulus, and abrasion wear during post-fire residual properties of high performance concrete. This research work will open up further scope to study the performance concrete quality.

\section{Acknowledgments}

Authors would like to thank material $\mathrm{Lab}$ at Civil Engineering Department, Faculty of Engineering, Menoufiya University, Egypt for wear test and Also, Authors would like to thank Mechanical Engineering Department, Faculty of Engineering, Menoufiya University, Egypt for heat treatment and mechanical measurement.

\section{References}

[1]. Phan, Long T.; Carino, Nicholas J.; Duthinh, Dat; and Garboczi, Edward, International Workshop on Fire Performance of High performance concrete, NIST, Gaithersburg, MD February 13-14, 1997 Proceedings, NIST Special Publication 919, National Institute of Standards and Technology, September 1997.

[2]. Comeau, Ed and Wolf, Alisa, Fire in the Chunnel, NFPA Journal, Volume 91, Number 2, National Fire Protection Association, Quincy, MA, March/April, 1997

[3]. Ulm, Franz-Josef, Fire Damage in the Eurotunnel, International Workshop on Fire Performance of High Performance Concrete, NIST Special Publication 919, National Institute of Standards and Technology, Gaithersburg, MD, September 1997.

[4]. Kilıc, A, Atis CD, Yas ar E, O* zcan F. "High-strength lightweight concrete made with scoria aggregate containing mineral admixtures". Cement Concrete Res 2003;33 (10):1595-1599.

[5]. Mydin MAcand Soleimanzadeh S "Effect of polypropylene fiber content on flexural strength of lightweight foamed concrete at ambient and elevated temperatures" Advances in Applied Science Research, 2012, 3 (5):2837-2846

[6]. Davim PJ. A note on determination of optimal cutting conditions for surface finish obtained in turning 
using of experiments. J Mater Process Technol 2001;116 (23):305308.

[7]. Nian CY, Yang WH, Tarng YS. Optimization of turning operation with multiple performance characteristics. J Mater Process Technol 1999; 95 (13):90-96.

[8]. Rahim A, Sharma U.K., Murugesan K., Sharma A., Arora P. " Multiresponse optimization of post-fire residual compressive strength of high performance concrete" Construction and Building Materials 2013; 38: 265-273

[9]. Harun Tanyildizi, Ahmet Coskun "Performance of lightweight concrete with silica fume after high temperature" Construction and Building Materials2008; 22 : 21242129.

[10]. Maya T.M and Nivin Philip "Mechanical Properties of Concrete Containing Roof Tile Aggregate Subjected to Elevated Temperature" IJIRAE2014; 1 (8): 2349-2163.

[11]. Qiu et al., Application of BoxBehnken design with response surface methodology for modelling and optimizing ultrasonic oxidation of arsenite with $\mathrm{H} 2 \mathrm{O} 2$, Central European Journal of Chemistry2014;12: 164-172.

[12]. RILEM TC 129-MHT. Test methods for mechanical properties of concrete at high temperatures - part 1: introduction; part 2: stress-strain relation: and part 3: compressive strength for service and accident conditions. Mater.Struct.1995; 28 (181):410-414.

[13]. Anderson, T., Fracture mechanics, fundamental and application, 2nd Ed., CRC press, Boca, USA,1995.

[14]. Yazici S, Inan G. An investigation on the wear resistance of high strength concretes. Wear 2006; 260: 615-618.

[15]. Cavdar A, Yetgin S. Investigation of abrasion resistance of cement mortar with different pozzolanic compositions and subjected to sulfated medium. Constr Build Mater 2010; 21: 461-470.

[16]. Kilic A, Atis CD, Teymen A, Karahan O, Ozcan F, Bilim C, et al. The influence of aggregate type on the strength and abrasion resistance of high strength concrete. Cem Concr Compos 2008; 30: 290-296. ,

[17]. Siddique R, Kapoor K, Kadri EH, Bennacer R. Effect of polyester fibres on the compressive strength and abrasion resistance of HVFA concrete. Constr Build Mater 2012; 29: 270-278.

[18]. Antony J, Antony JF. Teaching the Taguchi method to industrial engineers. Work Study 2001;50 (4):141-149.

[19]. Taguchi $G$, Introduction to quality engineering. Asian Productivity Organization, Tokyo1990.

[20]. Ross PJ, Taguchi technique for quality engineering, 2nd edn. McGraw-Hill, New York 1989.

[21]. Husen, M, The effect of high temperature on compressive and flexural strengths of ordinary and high performance concrete, Fire Safety J 2006; 41: 155-163

[22]. Yang H, Lin Y, Hsiao C, Liu JY. Evaluating residual compressive strength of concrete at elevated temperatures using ultrasonic pulse velocity. Fire Safety J 2009; 44: 121-130.

[23]. Balendran RV, Zhou FP, Nadeem A, Leung AYT., Influence of steel fibers on strength and ductility of normal and lightweight high strength concrete, Build Environ 2002;37:1361-1367.

[24]. D.C. Montgomery, Design and analysis of experiments, Wiley, New York. 2001.

[25]. Derringer G and Suich R, Simultaneous optimization of several response variables, J. Quality Techan., 1980; 12: 214-219. 